\title{
Interscript comparison of handwriting features leading to their identification and authorship
}

\author{
AMANPREET KAUR \\ Department of Forensic Science, Punjabi University \\ Patiala, India \\ MOHINDER SINGH
}

Former GEQD, CFSL, Directorate of Forensic Science Services

Government of India

OM PRAKASH JASUJA

Department of Forensic Science, Punjabi University

Patiala, India

\section{Introduction}

Linguistic diversity among different populations is a well established and recognized fact. Throughout the world thousands of spoken languages prevail which are written in hundreds of scripts. In India alone, 22 languages/scripts have been recognized by the Constitution. Both Hindi and Punjabi scripts belong to the same group of languages that is Indo Aryan and originated from the same script i.e. Sanskrit (Masica 1991). Hindi follows Devnagari script and Punjabi follows Gurmukhi script (Saxena and Singh 1992, and Jasuja et al. 1996). Devnagari and Gurmukhi both are descendants of the Brahmi script. Gurmukhi script was attained from the Sharda Script and systematized by Guru An- 
gad Dev Ji in $16^{\text {th }}$ century and was designed to write Punjabi (Gill and Gleason 1963, and Jasuja et.al 1996). Devanagari script is also used for writing Sanskrit and other Indian languages that originated over a period of more than 2000 years. Devanagari proliferated around 1200 AD from the Siddham script, side by side replacing the earlier closely related Sharda script (which remained in parallel use in Kashmir). Siddham and Sharda scripts are immediate descendants of the Gupta script, which are ultimately derived from the Brāhmī script (Goyal and Lehal 2008).

Most of the literate persons in India know at least three languages (scripts) i.e., Hindi (Devanagari), English (Roman) and one native language which may be Punjabi (Gurumukhi), Gujarati, Urdu, Tamil, Telugu, Malayalam, Bengali etc. Under this scenario, the necessity of exploring the possibility of inter script comparison of handwriting arises, because the sample handwritings supplied for comparison in the same script as that of the disputed writings may not be available due to various reasons and the investigating agency still wants some opinion or lead from the expert in the best interest of the case under examination. Another possibility may be that the examiner concerned is not well versed or having sufficient knowledge of either or all the scripts/ language involved in the process of comparison.

In such cases involving examination and comparison of unfamiliar scripts, it is debatable as to whether the examiner is at all capable and competent to express an opinion regarding the authorship. While most of the examiners consider such problems to be out of scope of the forensic document examination for the explicit reason that it violates the principle of like with like comparison due to non availability of similar letters and combinations between the questioned and the standard writings, for an effective comparison; others are of the view that handwriting being a product of neuromuscular activity and examination of handwriting follows the same principles, irrespective of the script/ language, it is still possible to furnish the opinion. Further, it cannot be denied that the examiner concerned may not be able to appreciate various forms of the stroke formation and usual variations around the master pattern of various letters in the unfamiliar or different scripts and clearly differentiate the extent and range of natural variations between them of the same person vis-à-vis 
the fundamental differences, which are due to different authorship; and hence, there remains a possibility of erroneous conclusion in such cases.

Apart from this, it has been observed that the same person may be employing different scripts for preparation of different categories of documents; it is quite possible that questioned and standard writings may not be available in the same script. Hence, firstly, there arises a need for the interscript comparison of the questioned and the standard writings. Secondly, in case inter-script or unfamiliar script comparison is to be attempted, it would be interesting to find out as to what handwriting features can be easily found and evaluated, and what other features cannot be found and compared. The purpose of this research is, therefore, to know whether it is possible to carry out inter-script comparison and, if yes, to highlight those features which could be successfully studied and evaluated and also consider those which could not be. Based on the evidential value of the observed features and significance of the eluding features, opinion regarding common authorship or otherwise can, therefore, be attempted.

\section{Materials and method}

The handwritten samples from 40 individuals skilled in writing in three scripts (Hindi, English and Punjabi) were collected with their consent. Three samples were collected in each script on a plain white paper sheet of A4 size with a blue ball point pen. Collected samples were then examined and analyzed by applying various principles of handwriting examination for the determination of similarities and closeness between the scripts, basics of each script, copybook form of each letter and its divergence from the copy book form in the individual's handwriting, analysis of overall pictorial appearance of the letter and word and other individual handwriting characteristics. Comparison of the samples is based on various class and individual characteristics. These characteristics include:

1. Alignment of handwriting with respect to the actual or imaginary baseline.

2. Size of the handwriting.

3. Slant of the vertical strokes.

4. Commencing and terminating strokes.

5. Angularity of strokes. 
6. Style of handwriting.

7. Similarities in the letters/ alphabets among the three scripts.

The control paragraphs for the three scripts are given in Appendix.

\section{Results and discussion}

All the samples were examined for the usual handwriting characteristics, such as:

- Alignment which is defined as the relation of line of handwriting with the imaginary baseline or headline (in case of scripts like Hindi, Punjabi, and Bengali etc.) (Jasuja et al. 1996). In all the writings, $30 \%$ were written with horizontal alignment while $35 \%$ writings were having descending alignment. $25 \%$ writings were found to be with mixed (uneven and arched) and $10 \%$ with ascending alignment. Though, the alignment of the writing in three scripts is observed in different manner, still it is clear from the figure that the same writer will have the tendency of alignment in similar way in all the writings. In $85 \%$ of the cases, the writing written by the same person in different scripts has been observed to have similar alignment, which cannot be attributed to chance occurrence (Figure 1).

(a)

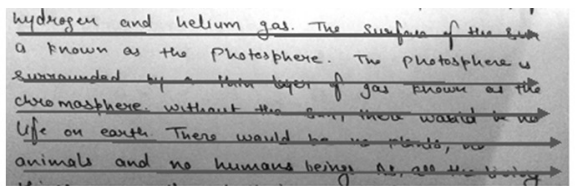

(b)

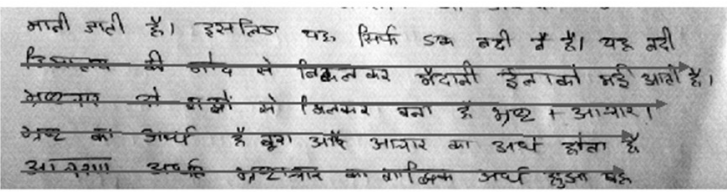

(c)

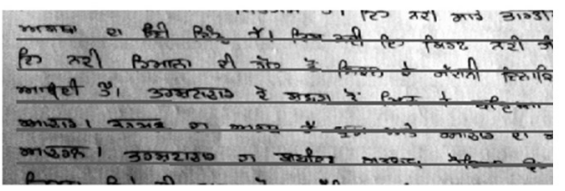

Figure 1. Shows the alignment of handwriting of an individual in the three different scripts (a) English (b) Hindi and (c) Punjabi, in all the cases the alignment of the handwriting is downhill 
- Size: the measurement of the handwriting letters with respect to the baseline. The overall size of the handwriting varies with the spaces left by the writer between the text, words or lines (Jasuja et al. 1996). In the present study, $85 \%$ of the writers wrote the writings with medium size. It was again interesting to note that $72 \%$ writers were having almost the same size of writing when they wrote in different scripts. The size of the writing of the same writer in three scripts has been shown in Figure 2.

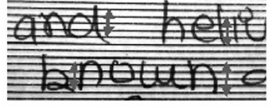

(a)

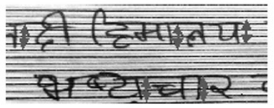

(b)

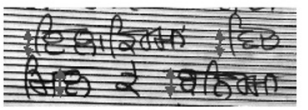

(c)

Figure 2. Shows that the size of (a) vertical stroke of letter 'd', letter 'i' and vertical strokes of letter 'n' of English, (b) vertical stroke of letter 'न', diacritic sign' $T$ ' and letter 'य' of Hindi and (c) diacritic sign ' $f$, vertical stroke of letter 'भ', letter 'm' and letter 'घ' of Punjabi have same size

\begin{tabular}{|l|l|}
\hline Handwriting characteristic & \multicolumn{1}{|c|}{ Description and type } \\
\hline \multirow{3}{*}{ SIZE } & Small $(1-3 \mathrm{~mm})$ \\
\cline { 2 - 2 } & Medium $(3.1-6 \mathrm{~mm})$ \\
\cline { 2 - 2 } & Large $(6.1 \mathrm{~mm}$ and above $)$ \\
\hline
\end{tabular}

- Slant wchich is defined as the angle of axis of stroke with the baseline (Hilton 1982). The slant of writing in an individual's writing is not fixed but varies within a range. Slant of writing of an individual varies from few degrees to 50 degrees (Osborn 1929). In the present study, it was interesting to note that in $60 \%$ of all the writings range of slant of the handwriting in three scripts written by the same person was found to be almost similar. In 30\% writings, the range of slant in Hindi and Punjabi writings is almost similar but the range of slant in English writing varies. In $10 \%$ of the cases, the range is totally different in each script. Basically the Punjabi population shows mixed type of slant which means that, in most of the cases, the range of slant varies from forward to backward like $89^{\circ}-120^{\circ}$ (Figure 3). Jasuja et al. (1996) and Turner et al. (2008) reported that most of the Punjabi writers wrote with upright slant. 


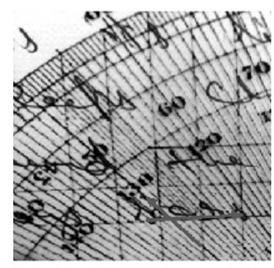

(a)

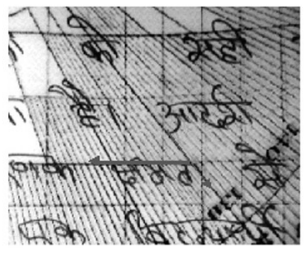

(b)

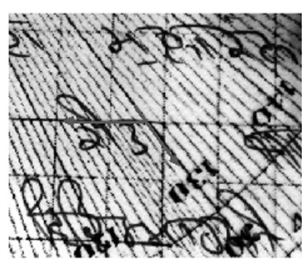

(c)

Figure 3. Shows that the slant of letter (a) 't' of English, (b) diacritic sign ' $T$ ' of Hindi and (c) 'r' of Punjabi script have same slant i.e. $130^{\circ}$.

- Commencing and terminating strokes: it is presumed that when a writer is able to write in more than one script, as in the present study, the writer is usually more skilled in the first learnt script, i.e., the mother tongue; but there is not much literature available on this aspect. Therefore, once we hypothesized about possible similarities in all the written scripts known to the person concerned, we started with the examination of skill of the writer. For this, a study of commencing and terminating strokes was undertaken. The strokes present at the starting point and at the ending point of a letter are defined as commencing and terminating strokes (Huber and Headrick 1999). As the writer simultaneously knows all the three scripts and could write with the same or similar level of skill, it has been found that the commencing and terminating strokes are flying and fine. In some cases, the terminating stroke ends with a little curve in writings of all the three scripts. Tapered initial and terminating strokes in all the three scripts have been indicated in Figure 4.

- Angularity of strokes: Osborn (1929) defined angularity as one of the fundamental features that can be used while analyzing handwriting samples. Angularity depends upon the speed of writing. Osborn also stated its three types i.e., angular, rounded and oblong or elliptical. Greater the speed, lesser will be the angularity.

\section{Angularity $=1 /$ speed}

As seen from the analysis, most of the writers used to write Punjabi and Hindi script in rounded form which is in accordance with earlier studies (Jasuja et al. 1996 and Turner et al. 2007). In this study, we found that most of the writers have written rounded form of writing and their writings in all the three scripts show similar type of angularity. In $80 \%$ 


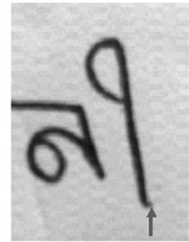

(a)

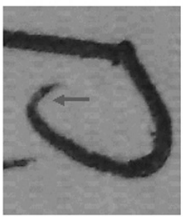

(d)

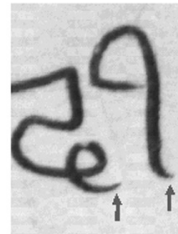

(b)

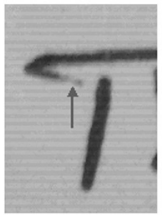

(e)

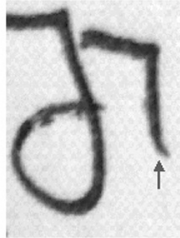

(c)

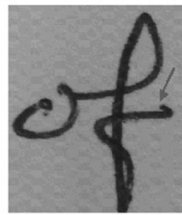

(f)

Figure 4. (a) and (b) shows the terminating strokes having very thin and curved line while writing in Hindi by an individual (c) and (d) shows the terminating and commencing strokes having a little curve in Gurumukhi script (e) and (f) shows the curve and a small hook at the termination stroke

of the cases, the angularity of writings in different scripts is found to be similar. In remaining $20 \%$, the writing in one of the script was found to be rounded and in other script, it was angular (Figure 5).

\begin{tabular}{|c|c|c|c|c|l|}
\hline S.NO. & Angularity & Hindi & Punjabi & English & \multicolumn{1}{c|}{ Observations } \\
\hline 1. & Angular & & $\begin{array}{l}\text { The writer has angular hand- } \\
\text { writing in all the three cases. } \\
\text { The arrows show the angular } \\
\text { strokes of letter 'ए', 'w' and } \\
\text { letter 'A'. }\end{array}$ \\
\hline 2. & Rounded & & $\begin{array}{l}\text { The writer has rounded hand- } \\
\text { writing in all the three } \\
\text { scripts. The strokes marked } \\
\text { by arrows in letter ' } \text { ', 'J' } \\
\text { and 'J' are rounded in shape. }\end{array}$ \\
\hline
\end{tabular}

Figure 5. Angularity in strokes

- Style: Style of the handwriting may be classified as cursive, manuscript (uppercase and lowercase letters but disconnected), hand lettering (capital letters) and composite (mixture of all other types) (Hu- 
ber and Headrick 1999). The style for Hindi and Punjabi scripts is in their copybook forms i.e. hand printing or hand lettering (Saxena and Singh 1992 and Jasuja et al. 1996) but in the English script, the style of handwriting is basically cursive i.e. the adjacent letters in the words have connection in between. But, as the person acquires the handwriting and changes it according to his ease, the intra-word connections in English and inter or intra-word connections in Hindi and Punjabi may develop (Jasuja et al. 1996, Turner et al. 2007 and Saxena and Singh 1992). In addition to this, in Devanagri and Gurumukhi scripts, letters of a word are joined together with the help of a headline as can be seen in Figure 6. On the other hand, the script in English has no such head line but letters of the word may be joined together with the help of connecting strokes between the letters. In $40 \%$ of the cases, the English scripts have cursive handwriting and Hindi and Punjabi writing of the same person has hand printing or manuscript form of handwriting. In $30 \%$ of cases, the English writing have composite style of handwriting. In $15 \%$ of the cases, the writers have manuscript of hand printing form of handwriting in all the three scripts. In remaining $15 \%$ of the cases, the cursive style of handwriting in Punjabi and English was found, whereas hand printed style of handwriting was found while writing in Hindi script. Only in one case, the person showed cursive handwriting in all the three scripts.

- Similarities in the letters/alphabets among the three scripts: handwriting is an acquired skill. An individual learns this art from his relatives, teachers and the copybooks provided for the particular

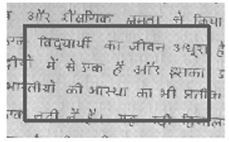

(a)

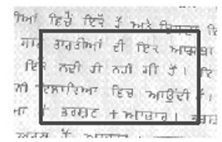

(b)

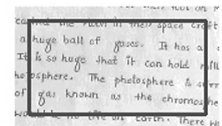

(c)

Figure 6. shows the style of handwriting, the style followed by the writer in figure $\mathrm{a}, \mathrm{b}$ and $\mathrm{c}$ shows that the individual follows the handpriting style in all the three scripts. Though the English handwriting is usually cursive one but in this case the letters are not connected with each other

script (Osborn 1929). But with the passage of time, according to his ease and pen scope the handwriting starts diverging from the copybook form. He just modifies the letters and words according to his ease and taste. In 
this way, each writer deviates from the copy book forms but acquires a master pattern for that particular stroke. All the deviations for that particular stroke remain around the master pattern.

Harrison (1996) and Huber and Headrick (1999) described, by quoting Ellis (1979), that a grapheme is the abstract representation of a letter and a word is spelled as a string of graphemes. They further described that the construction of the writing, finally, is pattern of ink on the paper representing a particular allograph, which is specific for that writer only. Any given allograph will be produced differently in the writings of different writers. We found this statement very correct and consider it as the basis of handwriting comparison and identification. In addition to this, we have observed that the same writer will write a particular allograph or part of allograph (stroke) in the same manner irrespective of script of the writing.

This very fact forms the basis of our study that writings of the same person, if written even in different scripts, could be compared with each other to arrive at an opinion regarding authorship. This fact may prove very helpful in designing computer-based text independent comparison of the writings where, instead of complete allograph, a part of the allograph is considered for the search in the data base so that faster search may be achieved. Moreover, the principle, "only likes can be compared" does not literally mean that writings to be compared must invariably be in the same script, but rather the similar stroke (grapheme). That means, even if a part of the allograph is drawn in the same manner, those can be considered as likes even if they originate from different scripts. In the present research, we have attempted to validate and demonstrate this assumption.

Devanagri and Gurumukhi scripts having the same origin, have many characters/alphabets in common and, therefore, there should be no problem to find many common strokes in sufficient number of alphabets; but the Roman (English) script being entirely different from these two is not considered to have much commonness. However, in the present study, we have shown that there are many strokes in English script also which can be considered consistent with similar Devanagri and Gurumukhi strokes. Figure 7A-7H demonstrates clearly this fact. Singh et al. (1994) mentioned that a writer may have influence of the vernacular characteristics of primary language (used commonly in their daily life) and idiosyncratic features on their secondary language. 
These idiosyncratic features may also be incorporated in their writings, when the real person tries to commit 'auto forgery', or otherwise that particular idiosyncratic feature may be found missing when somebody else tries to commit forgery of his writings. Though, we could not find any such idiosyncrasy in the collected writing samples, still we devised a new way to find commonness in these two scripts with English. It was observed that many strokes in all the three scripts can be said to be common and drawn in the same manner in one's writing. It was found that, in $70 \%$ of the handwriting of an individual in the three scripts, there are some letters/parts of letters which show similarities in their letter designs. The same is demonstrated below with the help of Figures 7A-H.

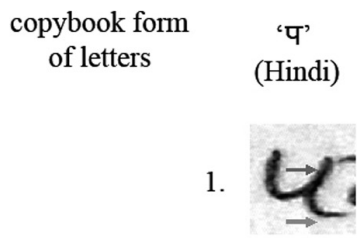

(a)

2 .

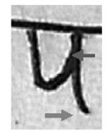

(a)

3.

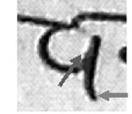

(a)

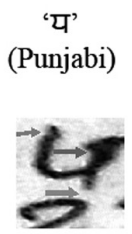

(b)

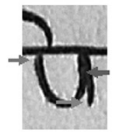

(b)

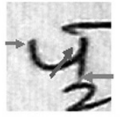

(b) 'u and y'

(English)

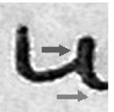

(c)

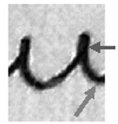

(c)

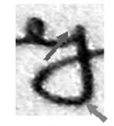

(c)

Figure 7A. Similarities between 'प'in Hindi, 'य' in Punjabi and ' $u$ or y' in English. These figures show the similarity among 'प', 'य' and upper part of ' $y$ ' or ' $u$ '. As it is shown in the image retracing is present at the same position in all the images (marked by red arrows). In case of copybook form of Punjabi letter 'प', a little curve is present which is found absent in these cases which make it lookalike Hindi letter ' $\square$ '(marked by green arrow). Termination stroke in each case is flying and in case of English letter ' $u$ ' is in continuation with the next letter (marked by blue arrow). 
copybook form of letters

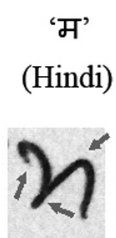

(a)

2.

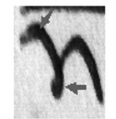

(a)

3.

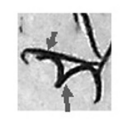

(a)

'म or भ' ' $\mathrm{n}$ '

(Punjabi) (English)

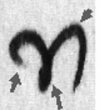

(b)

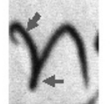

(b)

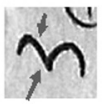

(b)

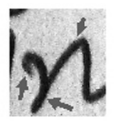

(c)

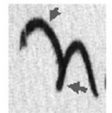

(c)

Figure 7B. Shows the similarity between letter 'म' of Hindi, the letter 'भ' and 'म' of Punjabi and letter ' $n$ ' of English. Retracing of the stroke in the middle is present in each case. The shoulders of all the letters are rounded and commencing and terminating strokes are flying and fine in all the three scripts. In case of Hindi and Punjabi letters the central connecting stroke is straight in copybook form as shown above but most of writers use to make it in slanting position and thus the letters become look alike English letter 'n'. 


\section{copybook form of letters}

‘ट’

(Hindi)

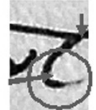

(a)

2.

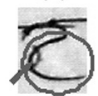

(a)

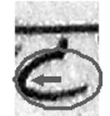

(a)

3.
'C' 'c'

(Punjabi) (English)

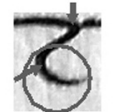

(b)

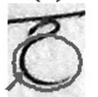

(b)

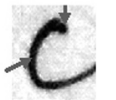

(c)

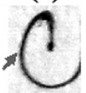

(c)

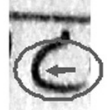

(b)

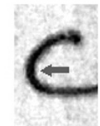

(c)

Figure 7C. Shows the similarity between the encircled stroke of letter 'C' of Hindi, and letter ' $\mathrm{C}$ ' of Punjabi and letter ' $c$ ' of English. In case of copybook form of Punjabi letter ' $C$ ' the curve is angular but most of the writers simplify the letter and make rounded stroke instead of angular stroke. Stroke between the headline and the curved part is missing which make it exactly lookalike English letter 'c'. The depth of rounded stroke is almost same in all the cases. 
copybook form of letters

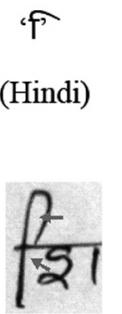

(a)

2.

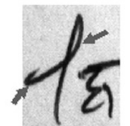

(a)

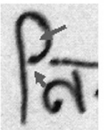

(a)

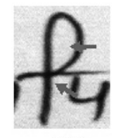

(b)

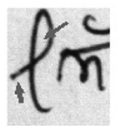

(b)

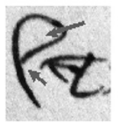

(b) 'f or p'

(English)

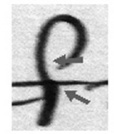

(c)

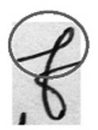

(c)

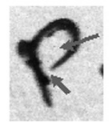

(c)

Figure 7D. Shows the similarity between diacritic sign ' $f$ ' in Hindi and Punjabi and English letter ' $\mathrm{f}$ '. The crossbar in each case is present at the same position and the upper portion of the letter ' $\mathrm{f}$ ' and diacritic sign makes a hairpin like loop. The encircled portion of letter ' $\mathrm{f}$ ' and diacritic signs shows similarity. In this case the commencing stroke is enlarged and ended up with a hairpin loop. Similarity between diacritic sign ' $f$ ' in Hindi and Punjabi and English letter ' $p$ ' is shown. A little gap is there between the staff and the bowl. Small loop is present in all the three cases. 


\section{copybook form of letters}

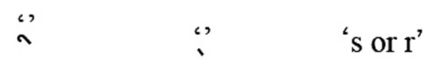

\section{(Hindi) (Punjabi) (English)}

1.

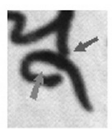

(a)

2.

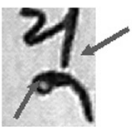

(a)

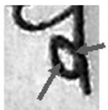

(a)

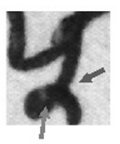

(b)

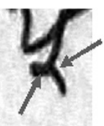

(b)

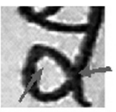

(b)

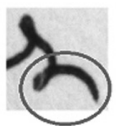

(c)

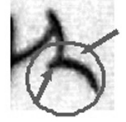

(c)

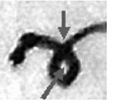

(c)

Figure 7E. The encircled portion of letter's' (English) and diacritic sign "' (Hindi), "'(Punjabi) have similarity among them. The encircled portion of 's' and diacritic signs ', (Hindi) and ''(Punjabi) have an eyelet and the handwriting movement followed by the writer in all the three cases is same and the letter 's' and both diacritic signs ends up with flying termination stroke. The letter ' $r$ ' (English) and diacritic sign ', (Hindi), "(Punjabi)have similarity among them. An eyelet is present in all the three letters and they are in continuation with their previous stroke. 


\section{copybook form of letters}

$\begin{array}{ccc}\text { ‘र’ } & \text { ‘ঠ’ } & \text { ‘k’ } \\ \text { (Hindi) } & \text { (Punjabi) } & \text { (English) }\end{array}$

1.

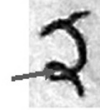

(a)

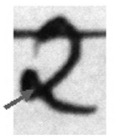

(a)

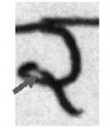

(a)

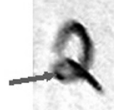

(b)

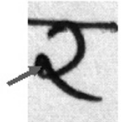

(b)

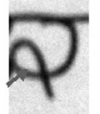

(b)

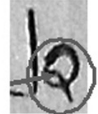

(c)

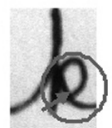

(c)

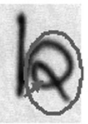

(c)

Figure 7F. This figure shows the similarity between the encircled portion of English letter ' $k$ ', Hindi letter ' ' and

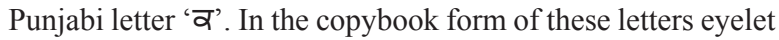
is present only in Punjabi letter ' $\overline{\text { ' }}$ but most of the writers use to make an eyelet in Hindi letter ' $₹$ ' and buckle of English letter ' $\mathrm{k}$ '. The encircled portions i.e. buckle of letter of ' $\mathrm{k}$ ' have an eyelet as shown by arrow and follows the same line of movement as Hindi letter ' $\mathrm{Y}$ ' and Punjabi letter ' $\boldsymbol{\alpha}$ '. 


\section{copybook form \\ of letters}

'ए'

(Hindi)

1.

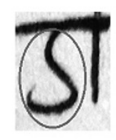

(a)
'ह'

(Hindi)

2.

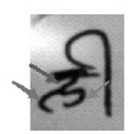

(a) $\therefore$

(Punjabi) (English)

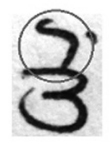

(b)

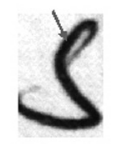

(c)

copybook form of letters

' $\mathrm{h}$ '

(Punjabi) (English)

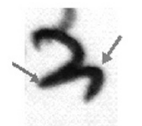

(b)

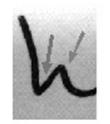

(c)

Figure 7G. Some miscellaneous examples are given which are found in some special cases. The encircled part of Hindi letter 'ए' and diacritic sign "' of Punjabi have similar design like letter's' of the English script. The difference among these three is that the letter's' has a small eyelet at the commencing stroke which is absent in the other two i.e. 'ए' and '". The marked stroke of letter 'ए' has a curve which makes it lookalike letter's'. Similarity among letter 'ह' of Hindi, letter ' $\delta$ ' of Punjabi and letter ' $h$ ' of English is shown. The design of letter 'ह' is similar to the design of letter ' of the Punjabi script because the individual execute a stroke that is present in the copybook form (marked by the red arrow). The letter has retracing at same position (marked by green arrows) and the shoulders are circular in case of letter 'ह' of Hindi, letter ' ' of Punjabi but pointed in case of ' $h$ ' (marked by blue arrows). 


\section{copybook form of letters}

'ए”

(Hindi)

1.

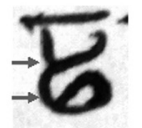

(a)

2.

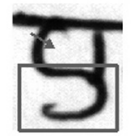

(a)

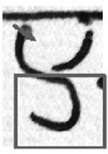

(a)

3.

'प'

(Punjabi)

(English)

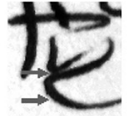

(b)

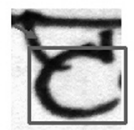

(b)

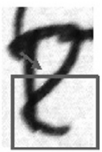

(b)

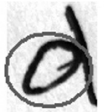

(c)

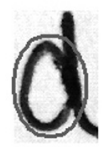

(c)

Figure 7H. The writer makes Hindi letter 'ए' as Punjabi letter ' $\mathrm{C}$ ', these two also have similarity with the encircled part of English letter' $d$ '. The upper part of letter ' $ए$ ' is connected with each other which makes it looking alike Punjabi letter ' $\mathrm{C}$ '. The rounded portion of letter' $d$ ' is similar to these two letter because the circular portion of letter' $d$ ' have same form and dimension. An eyelet is there in case of letter 'ए' which is absent in rest two cases. In figure 2 and 3 letter ' $ए$ ' is mirror image of Punjabi letter ' $\square$ '. The squared portion is mirror image in both the cases. The upper portion is same in both cases. The encircled part of letter'd' is look alike Punjabi letter 'प' and opposite to the squared portion of Hindi letter ' $ए$ '.

In some cases, these letter forms have pictorial differences between English script and the other two scripts; but when carefully observed, one can notice the similarities in manner of formation of the strokes. These differences were, however, not observed between Devnagari and Gurumukhi scripts. 


\section{Conclusions and limitations}

It follows that the best results can be achieved if the handwriting comparison is carried out with the similar letters and combinations, preferably in the same or similar scripts, by the expert who has sufficient knowledge of copy book forms and usual variations around their master patterns so that he can clearly differentiate between the usual and the unusual; natural and the unnatural characteristics of handwriting as well as differentiate fundamental differences from natural variations; which are necessary to arrive at a correct opinion regarding their authorship. However, if due to some reason, same script handwriting samples are not available for comparison, or comparison has to be attempted with the unfamiliar scripted writings only; comparison between the like strokes or basic elements of handwriting across the scripts can be attempted.

Success achieved in such cases of inter-script comparison shall depend upon the availability of suitable and sufficient features from the restricted study and their correct analysis and interpretation by a wellqualified, trained and experienced examiner and final conclusions have to be drawn keeping in mind the evidential value of observed handwriting features and significance of other characteristics which could not be observed, because the two sets of writings were not fully comparable.

Limitations imposed by nature of the problem at hand as well as capability of the expert who is assigned the job must also be kept in mind before expressing a final opinion in the matter. The final conclusions drawn by the expert must be appropriately worded and qualified so as to avoid the possibility of error in evaluation and interpretation and consequent miscarriage of justice.

The authors also propose to extend the scope of the present work to a few actual or simulated case studies, wherein suitable and sufficient quantity of disputed handwriting texts in one script will be actually examined and compared with handwriting samples in other scripts containing similar strokes of writings by several document experts who may be competent enough by virtue of their qualification, research aptitude and appropriate level of training and experience in their field of study. It would be quite interesting to find out if, on the basis of script independent or inter-script comparison; correct results could be arrived at, regarding their identifica- 
tion and authorship. The problems involving elimination of writer are usually much more difficult and complex than those of identification.

In view of the inherent limitations imposed by inter script comparison, we do not expect that the experts would be able to offer complete or even partial solutions to complex and diverse nature of problems involving handwriting identification and authorship, detection of forgery and fixing the authorship of forged writing/signatures with the writings of the suspect. However, even if they succeed in offering qualified conclusions or leads, in a few cases, for further investigation; it would undoubtedly be found useful to the stakeholders, as they have nothing to lose from such adventure.

Appendix. Paragraph in three scripts used for the present study

\section{ॐ मेरा अध्यापक ॐ}

हम सब के जीवन में शक्षिषा का बहुत महत्व है । इस शक्रिषा को सही रासतता एक आदरश अधियापक ही दे सकता है । आदरश अध्यापक का आलंकन उसके चरतिर और शैकषणकि कषमता से कयि जाता है । एक अध्यापक के बनि एक वद्यियारथी का जीवन अध्रा है। गंगा नदी भारत की प्राचीन नदयों में से एक है और इसका एक अपना इतहीस है । यह नदी सब भारतीयों की आस्था का भी परतीक मानी जाती है । इसलए यह सरिफ एक नदी नै है। यह नदी हमिलय की गोद से नकिलकर मैदानी इलाको मई आती है। भ्रष्टाचार दो शब्दों से मलिकर बना है भूरष्ट + आचार। भूरष्ट का अर्थ है बुरा और आचार का अर्थ होता है आचरण अर्थात भिरष्टाचार का शाब्दकि अरुथ हुआ वह आचरण जो कसिी भी प्रकार से अनैतकि और अनुचति हो ।

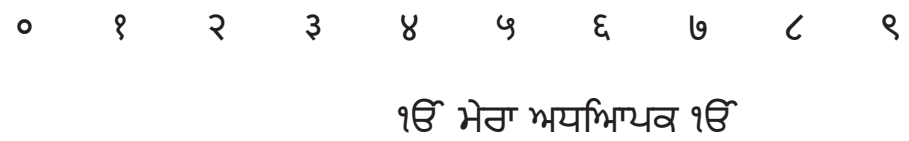

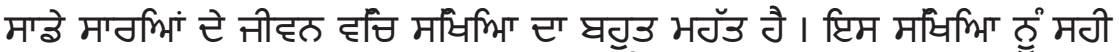

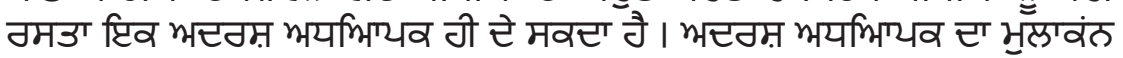




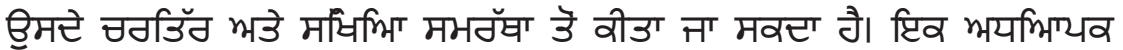

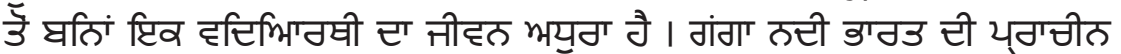

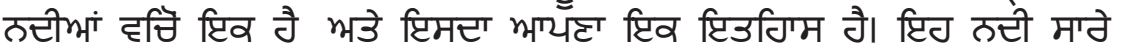

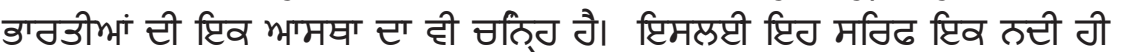

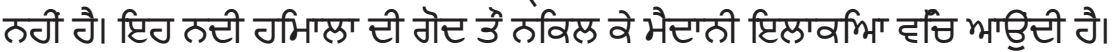

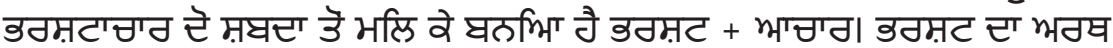

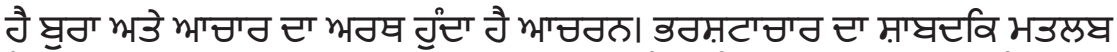

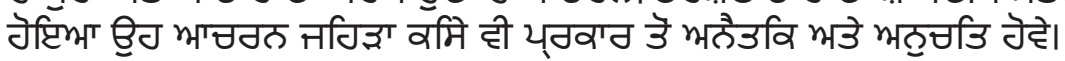

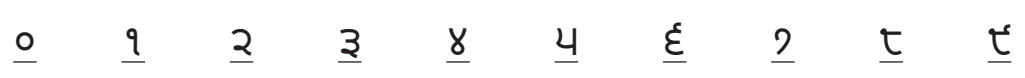

Moon and Sun

The Moon is a barren, rocky world without air and water. It has dark lava plain on its surface. The Moon is filled with craters. It has no light of its own. It gets its light from the Sun. The Moo keeps changing its shape as it moves round the Earth. It spins on its axis in 27.3 days stars were named after the Edwin Aldrin were the first ones to set their foot on the Moon on 21 July 1969 They reached the Moon in their space craft named Apollo II. The sun is a huge ball of gases. It has a diameter of 1,392,000 km. It is so huge that it can hold millions of planets inside it. The Sun is mainly made up of hydrogen and helium gas. The surface of the Sun is known as the photosphere. The photosphere is surrounded by a thin layer of gas known as the chromospheres. Without the Sun, there would be no life on Earth. There would be no plants, no animals and no human beings. As, all the living things on Earth get their energy from the Sun for their survival.

\section{References}

Ellis A.W. (1979), "Slips of the pen", Visible Language 13(3), p. 273.

Gill H. and Gleason H.A. (1963), A Reference Grammar of Punjabi. Patiala: Punjabi University Publication.

Goyal V. and Lehal G.S. (2008), "Comparative study of Hindi and Punjabi language scripts", Journal of Linguistic Society of Nepal 23, pp. 67-82.

Harrison W.R. (1958), Suspect Documents \& Their Scientific Examination, Sweet and Maxwell Limited, U.K. 
Jasuja O.P. and Komal (1996), "Examination of Gurmukhi script: a preliminary report", Science and Justice 36(1), pp. 9-13.

Hilton O. (1993), Scientific Examination of Questioned Documents, CRC Press, Inc., 2000 Corporate Blvd., N.W., Boca Raton, Florida.

Masica C.P. (1991), Indo-Aryan Languages, Cambridge: Cambridge University Press.

Osborn A.S. (1929), Questioned Documents, Boyd Printing Co., Albany, N.Y., USA.

Saxena H.M. and Singh M. (1992), "Classification of the writing elements in Devanagri scripts", "Journal of Forensic Science Society", 32(2), pp. 143-150.

Singh A., Gupta,S.C. and Saxena H.M. (1994), "Influence of the primary language and idiosyncratic features in simple forgeries”, Journal of Forensic Science Society 34(2), pp. 83-87.

Turner I.J., Sidhu R.K. and Love J.M. (2008), “A preliminary study investigating class characteristics in Gurmukhi handwriting of $1^{\text {st }}$ and $2^{\text {nd }}$ generation Punjabis", Science and Justice, 48, pp. 126-132.

\section{Summary}

Identification of handwriting found on the disputed document by comparison with the known handwriting samples of the suspect still comprise the problem which is most commonly referred to a forensic document examiner. One of the important scientifically established principles which govern such analysis and identification is the 'Principle of Comparison' which explicitly states that, for obtaining correct results, like has to be compared with like; meaning thereby that the expert has to analyze and rely upon similar letters and combinations between the questioned and the standard handwriting samples and, consequently, the problems where similar handwriting samples in the same script have not been provided for comparison; usually fall outside the scope of forensic document examination. However, in this field, like any other human activity; perfect and ideal conditions are hard to achieve.

Handwriting, being acquired skill and neuro-muscular controlled motor activity, its basic elements like the horizontal stroke, vertical stroke, loops, curves and arches etc., are combined together to form letters and alphabets of all the scripts. The question then arises - whether inter-script comparison of handwriting samples can be attempted leading to some limited or qualified conclusions. Thus, if it becomes possible and practicable to examine and compare the basic elements of questioned handwriting in one script, say Devanagri with the similar elements found in specimen/ admitted handwriting samples in another script by the same writer, say Gurmukhi, (because sample handwritings in Devanagri could not be procured for whatsoever reasons); the scope of examination can be widened further and expert may be in a position to express some opinion (regarding their common authorship or otherwise), which may be found worthwhile to the investigating agency or the court of law, thereby helping in the administration of justice ultimately.

To the best of our knowledge, not much research is available, where writings produced in different scripts by the same writer could be compared, thereby leading to a definite opinion on the issue of their common authorship or otherwise. In the present study, an attempt 
has been made to explore this issue by taking writing samples of the same writer in three scripts, having knowledge of all the three commonly used languages, i.e., English, Hindi, and Punjabi, corresponding to the said scripts (i.e., Roman, Devanagari and Gurumukhi). Three hundred sixty (360) writing samples were obtained from as many as (40) individuals appropriately skilled in writing, reading and speaking these languages/ scripts.

Careful study and evaluation of the basic elements of written strokes whose execution were found to be similar in all the three scripts has been carried out indicating the possibility of 'Script Independent Comparison'. Limitations of the proposed study have also been discussed in the paper.

Keywords: unfamiliar, script, forensic examination, handwriting, Punjabi, Hindi, English. 